\title{
Comparative study of dexamethasone nebulisation with magnesium sulphate nebulisation in preventing post operative sore throat following endotracheal intubation
}

\author{
Ashwini $\mathbf{H}^{1}$, Seema Kumari $\mathbf{K}^{2, *}$, Lavanya $\mathbf{R}^{3}$ \\ ${ }^{1}$ Associate Professor, ${ }^{2}$ Assistant Professor, ${ }^{3}$ Statisfician, Dept. of Anaesthesia, Sapthagiri Institute of Medical Sciences and \\ Research Centre, Karnataka, India
}

*Corresponding Author:

Email: drseemavbhat@gmail.com

Received: $16^{\text {th }}$ April, 2018

Accepted: $30^{\text {th }}$ April, 2018

\begin{abstract}
Introduction: Post-operative sore throat is one of the most common complications following endotracheal intubation. Though considered minor complication, it may cause significant patient dis-satisfaction. Various non-pharmacological and pharmacological trials have been used with variable results.

Objectives: To compare the efficacy of nebulised dexamethasone with that of nebulised magnesium sulphate in decreasing the incidence and severity of postoperative sore throat (POST).

Materials and Methods: In this prospective double blind study 90 patients undergoing surgery under general anaesthesia with endotracheal intubation lasting <3hr were randomly assigned into two equal groups. Group D received dexamethasone $8 \mathrm{mg}(2 \mathrm{ml})$ with $3 \mathrm{ml}$ saline nebulisation and group $\mathrm{M}$ received magnesium sulphate $(50 \% \mathrm{~W} / \mathrm{V} 2 \mathrm{ml})$ with $3 \mathrm{ml}$ saline nebulisation 30 min before the induction of anaesthesia. Primary outcome assessed was incidence and severity of POST. Secondary outcome assessed were the incidence of post-operative hoarseness and cough.

Results: Compared to group M, significantly lesser number of patients in group D had post-operative sore throat at $0 \mathrm{hr}(\mathrm{p}=$ $0.0262), 4^{\text {th }} \mathrm{hr}(\mathrm{p}=0.00022), 8^{\text {th }} \mathrm{hr}(\mathrm{p}=0.00039)$ and $12 \mathrm{hr}(\mathrm{p}=0.000657)$. None of the patients in group D had any hoarseness of voice at $0 \mathrm{hr}, 4^{\text {th }} \mathrm{hr}, 8^{\text {th }} \mathrm{hr}$ of assessment $(\mathrm{p}=<0.05)$. Except one patient in group $\mathrm{M}$, none of our patients in either of the group had cough at any point of assessment.

Conclusion: Preoperative dexamethasone nebulisation just before induction of anaesthesia is an effective method of reducing the incidence and severity of POST following endotracheal intubation. Dexamethasone nebulisation reduces the severity of sore throat more effectively than magnesium sulphate nebulisation.
\end{abstract}

Keywords: Postoperative sore throat, Nebulisation, Hoarseness, Cough, Dexamethasone, Magnesium sulphate.

\section{Introduction}

Sore throat is one of the common postoperative complaint that leads to morbidity and patient dissatisfaction. It is $5^{\text {th }}$ most frequent adverse clinical anaesthesia outcome. ${ }^{1}$ The incidence of sore throat has been reported to be very high [21\%-65\%]. ${ }^{2}$ Irritation and inflammation of the airway, mechanical injury during intubation, damage to the mucosa due to the pressure from the endotracheal tube cuff and dehydration of the mucosa were considered the cause of postoperative sore throat (POST). ${ }^{3,4}$ Although symptoms subside without any treatment, the management for POST is still advised because it enhances patient satisfaction, acceptance of anaesthesia and improves the activities after discharge. ${ }^{5}$

Prophylactic management of POST is recommended to improve the quality of anaesthesia care of duration of time a patient stays in the postanesthesia care unit because of POST increases the cost of care. Patients with POST had a 14min longer stay in the post anaesthesia care unit and 25 min longer stay in the ambulatory care unit and were discharged $51 \mathrm{~min}$ later from the facility compared with those who did not complain of POST. ${ }^{5}$
Different agents like ketamine gargle $^{6}$ and nebulisation, ${ }^{7}$ endotracheal tube spraying with Beclomethasone, ${ }^{8}$ intravenous injection of dexamethasone, ${ }^{9}$ magnesium sulphate gargle $^{10}$ and Lozenges ${ }^{11}$ nebulized lignocaine, ${ }^{12}$ lignocaine jelly have been used with variable success for decreasing both the incidence and severity of POST.

Corticosteroids are used in the perioperative period to enhance the effects of analgesics and antiemitics. Inhaled carticosteroids deliver the drug to the airways without systemic effects. Dexamethasone is a potent steroid that has 26.6 and 6.6 times stronger antiinflammatory and immune-suppressant effects than cortisol and prednisone, respectively. It has been supported that it is very useful for relieving POST. ${ }^{13,14}$ Therefore, inhaling dexamethasone may be used as a method to reduce POST following general anesthesia [GA].

As proven by previous studies N-methyl Daspartate [NMDA] receptors are involved in nociception and inflammation. ${ }^{15,16}$ NMDA receptors are present all over the nervous system. Magnesium is an antagonist of the NMDA receptors and prevents the central sensitization of peripherally inflicted nociceptive stimulus. Nebulisation will deliver the drug 
to the airways with no or minimal systemic effects. Both magnesium sulphate and dexamethasone are readily available in the operation theatre. Present study was done to compare the efficacy of dexamethasone nebulisation pre-operatively with that of magnesium sulphate nebulisation. In addition we also observed for other airway related complaints like hoarseness and cough, postoperatively

\section{Materials and Methods}

This was a prospective double blind randomised study conducted after obtaining approval from our hospital ethical committee (IEC NO: SIMS \& RC/IECC/05/2017). Written informed consent was obtained from patients after proper explanation regarding the study. ASA1 \& ASA2 physical status patients aged between 20 to 50yrs admitted for elective surgery under general anaesthesia with endotracheal intubation with mallampatti score 1-2, undergoing surgeries lasting less than 3 hrs duration were selected for the study. 90 patients were chosen by simple chit picking method into two groups of 45 patients each. To show $50 \%$ reduction in the incidence of POST (which is reported to be $65 \%$ ) at $\alpha=0.05$, confidence interval of $95 \%$ and a power of $90 \%$, we required 30 patients each group. On adding $10 \%-15 \%$ patients loss due to multiple attempts at laryngoscopy and due to bucking during extubation, each group needed 40 to 45 patients.

Patients with history of sore throat, on long term anti-inflammatory analgesic medications, patients who have undergone insertion of devices which stimulate oral cavity, larynx, pharynx like nasogastric tube, endoscopic nasobiliary drainage tube, mallampatti grading $>2$, patients who are undergoing head and neck surgeries, patients who needed more than two attempts at endotracheal intubation and use of bougie and styllete, obese, diabetic, pregnant patients, surgeries lasting for more than $3 \mathrm{hrs}$, surgeries in prone position were excluded from the study.

Group D received dexamethasone $8 \mathrm{mg}$ [2 $\mathrm{ml}]$ with $3 \mathrm{ml}$ of normal saline for nebulisation.

Group M received MgSo4 [50\% W/V 2ml] with $3 \mathrm{ml}$ of normal saline for nebulisation $30 \mathrm{~min}$ before the induction of anaesthesia in the preoperative receiving room. The patients were nebulised using mask connected to wall mounted oxygen driven source. (81t, 50psi) A nurse blinded for the study nebulised the patient using the study drug prepared by an anaesthesiologist not involved in the study. All the intubations were done by an anaesthesiologist with $>5 y$ rs experience. All patients were kept nil oral overnight and were premedicated with table. Ranitidine $150 \mathrm{mg}$ and table. Alprazolam 0.5mg $2 \mathrm{hrs}$ before the surgery.

After the nebulisation for $30 \mathrm{~min}$ in the receiving area, patients were shifted into the OT.

Monitoring included non-invasive blood pressure [NIBP], SPO2, ECG and capnography.
Patient premedicated with inj.glycopyrrolate $0.2 \mathrm{mg}$ and midazolam $1 \mathrm{mg}$. Injection fentanyl 1 was given $2 \mathrm{mcg} / \mathrm{kg}$. Patient was induced with inj. propofol $2 \mathrm{mg} / \mathrm{kg}$. Intubation was done using non-depolarising muscle relaxant, inj.Vecuronium $0.15 \mathrm{mg} / \mathrm{kg}$. Intubation was performed as smooth direct laryngoscopy after 4 min of injecting vecuronium. Endotracheal tube size 7 was selected for females and 8 was selected for males. A single use portex high volume low pressure cuffed endotracheal tube was used for the intubation. Patient were excluded from the study if intubation failed in two attempts or $\mathrm{O} 2$ saturation dropped below $95 \%$ during intubation. Anaesthetic gas mixture was used to inflate the endotracheal tube cuff till no leak was heard around the tube. Cuff pressure was adjusted to $20-22 \mathrm{CmH} 2 \mathrm{O}$ using cuff inflator/ pressure gauge PORTEX TM. Cuff pressure was monitored every half an hour to maintain the cuff pressure of 20 to $22 \mathrm{CmH} 2 \mathrm{O}$.

Maintenance of anaesthesia was the same in both the groups using isoflurane $1 \mathrm{MAC}$ and vecuronium divided doses with $50 \% \mathrm{O} 2+50 \% \mathrm{~N} 2 \mathrm{O}$. $20 \mathrm{~min}$ before the completion of the procedure inj. ondansetron $4 \mathrm{mg}$ and inj.pethidine $0.5 \mathrm{mg} / \mathrm{kg} \mathrm{mg} \mathrm{IV} \mathrm{was} \mathrm{given} \mathrm{to} \mathrm{prevent}$ post operative nausea and vomiting and bucking on the tube respectively. Neuromuscular blockade was reversed using neostigmine $0.05 \mathrm{mg} / \mathrm{kg}$ and glycopyrrolate $0.001 \mathrm{mg} / \mathrm{kg}$. Gentle suctioning of oropharynx was done. Extubation was performed using the same method in both the groups when the patient was fully awake. Patients who bucked or coughed during extubation were excluded from the study. In the recovery room patient received $\mathrm{O} 2$ by mask $51 \mathrm{t} / \mathrm{min}$ and inj. Paracetamol $1 \mathrm{gm} 8^{\text {th }} \mathrm{hr}$.

Assessment: Patients were assessed in the postoperative ward by a nursing staff blinded for the study. Incidence of sore throat, discomfort, pain and other symptoms were assessed at the time of shifting to postoperative ward [0hr], 4hr, $8 \mathrm{hr}, 12 \mathrm{hr}$ and $24 \mathrm{hrs}$ according to the grading shown in Fig.1.

\begin{tabular}{lc}
\hline SEVERITY & Grade \\
\hline POST & 0 \\
$\begin{array}{l}\text { No sore throat at any time since the operation } \\
\text { Minimal - patient answered in the affirmative when }\end{array}$ & 1 \\
$\begin{array}{l}\text { asked about sore throat } \\
\text { Moderate - patient complained of sore throat on his/ }\end{array}$ & 2 \\
her own & 3 \\
$\begin{array}{l}\text { Severe - patient is in obvious distress } \\
\text { Post-operative cough }\end{array}$ & 0 \\
$\begin{array}{l}\text { No cough at any time since the operation } \\
\text { Minimal }\end{array}$ & 1 \\
$\begin{array}{l}\text { Moderate } \\
\text { Severe }\end{array}$ & 2 \\
Post-operative hoarseness of voice & 3 \\
$\begin{array}{l}\text { No complaint of hoarseness at any time since the } \\
\text { operation }\end{array}$ & 0 \\
$\begin{array}{l}\text { Minimal - minimal change in quality of speech. Patient } \\
\text { answers in the affirmative only when enquired about }\end{array}$ & 1 \\
$\begin{array}{l}\text { Moderate - moderate change in quality of speech of } \\
\text { which the patient complains on his/her own }\end{array}$ & 2 \\
$\begin{array}{l}\text { Severe - gross change in the quality of voice perceived } \\
\text { by the observer }\end{array}$ & 3 \\
\hline POST - Post-operative sore throat
\end{tabular}

Fig. 1 
Total incidence of POST was calculated by dividing the number of patients who experienced postoperative throat pain at least once by the total number of patients. The patients were then examined to determine the occurrence of any other postoperative complications and the findings were recorded in detail. Patients who had POST grading more than 2 were instructed to gargle aspirin $75 \mathrm{mg}$ dispersible tablet.

\section{Statistical Analysis}

The collected data was analysed using statistical package for social sciences (SPSS, V-20) Descriptive and inferential statistical analysis has been carried out in the present study.

Results on continuous measurements are presented on Mean \pm SD and results for $P$ value were calculated using t-test. Categorical measurements are presented in number. Chi square test is used to compare the difference in each group. Significance was assessed at $5 \%$ level of significance. If $\mathrm{P}<0.005$ is considered statistically significant.

\section{Results}

From Aug 2017 to March 2018, 90 patients were enrolled for the study. Three patients in group $\mathrm{M}$ were excluded due to bucking during extubation. Two patients in group D were excluded due to insertion of nasogastric tube and two patients bucked during extubation. So for statistical analysis we considered 40 patients in each group. Both groups were comparable with respect to age, distribution of sex, ASA physical status, duration of surgery (Table 1). Nearly $85 \%$ of patients in group $\mathrm{M}$ were intubated in first attempt where as $15 \%$ of patients were intubated in second attempt. In group D $82.5 \%$ of patients were intubated in first attempt and $17.5 \%$ were intubated in second attempt. This was not statistically significant $(\mathrm{P}=0.338)$. POST (at rest and on swallowing), cough and hoarseness of voice were assessed at $0,4,8,12$ and 24 hrs according to the scales shown in the Fig. 1.

Table 1

\begin{tabular}{|c|c|c|c|}
\hline Parameters & Group M & Group D & P-value \\
\hline Age & $37.65 \pm 10.060$ & $36.88 \pm 9.053$ & 0.228 \\
\hline Duration of Surgery & $112.83 \pm 38.046$ & $119.93 \pm 36.287$ & 0.336 \\
\hline \multicolumn{4}{|l|}{ Gender } \\
\hline Male & 25 & 26 & \multirow[b]{2}{*}{0.816} \\
\hline Female & 15 & 14 & \\
\hline \multicolumn{4}{|l|}{ ASA } \\
\hline 1 & 29 & 33 & \multirow[b]{2}{*}{0.284} \\
\hline 2 & 11 & 7 & \\
\hline \multicolumn{4}{|l|}{ No of attempts } \\
\hline 1 & 34 & 33 & \multirow[b]{2}{*}{0.338} \\
\hline 2 & 12 & 7 & \\
\hline
\end{tabular}

Incidence of POST was $27.5 \%$ in group D and $57.5 \%$ in group $\mathrm{M}$ and the difference was statistically significant at all times of assessment. (Table 2). Compared to group $\mathrm{M}$, the number of patients in group $\mathrm{D}$ who had POST were significantly low at rest at $0 \mathrm{hr}$ $(\mathrm{p}=0.0262), 4^{\text {th }} \mathrm{hr}(\mathrm{p}=0.00022), 8^{\text {th }} \mathrm{hr}(\mathrm{p}=0.00039)$ and $12 \mathrm{hr}(\mathrm{p}=0.000657)$. (Table 2). Also duration of pain relief was significantly longer (12hrs) in group D compared to group $\mathrm{M}(\mathrm{P}=0.000657)$. Only one patient in each group had POST at $24 \mathrm{hr}$ which was statistically not significant. $(\mathrm{P}=1.00)$ (Table 2)

Incidence of pain on swallowing was also more in patients in group $\mathrm{M}$ at all points of assessment compared to group D. (Table 2). Though the highest incidence of sore throat occurred at $4^{\text {th }} \mathrm{hr}$ postextubation in both the groups, it showed declining trend. This decline was significant in group D. (Table 2)

None of the patients in group D had postoperative hoarseness which was statistically significant at $0 \mathrm{hr}$, $4^{\text {th }} \mathrm{hr}, 8^{\text {th }} \mathrm{hr}$ of assessment. At $24 \mathrm{hrs}$ none of the patients in both the study groups had any hoarseness. (Table 2)

None of the patients in group D had cough at any point of assessment where as one patient in group $\mathrm{M}$ had cough at $4^{\text {th }} \mathrm{hr}$ and $8^{\text {th }} \mathrm{hr}$ which was clinically and statistically not significant. $(\mathrm{P}=1.00)$ (Table 2$)$ 


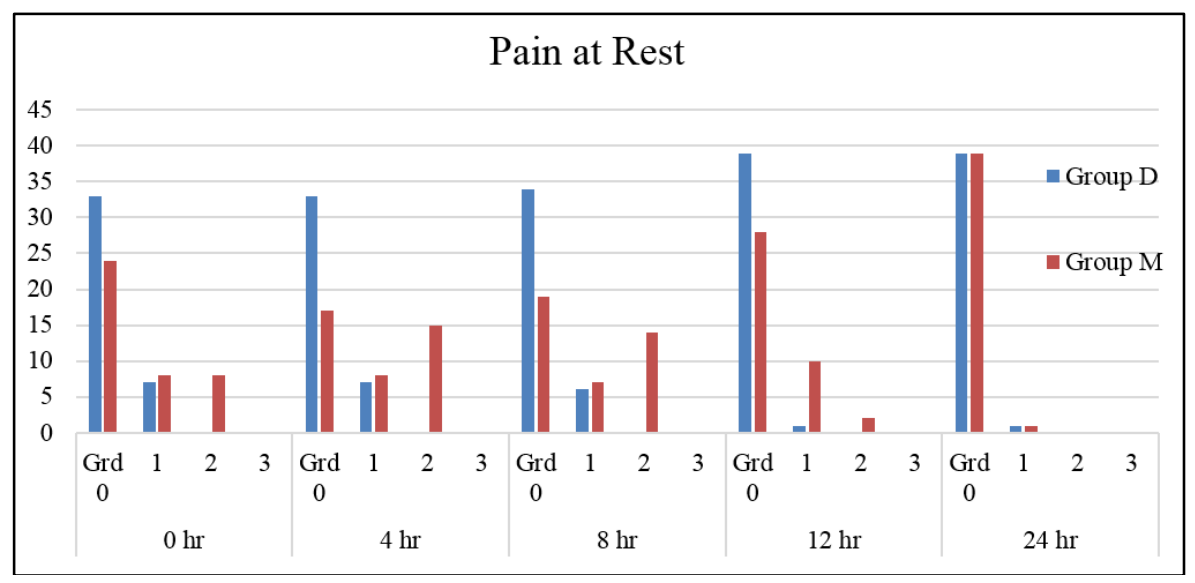

Fig. 2

This graph shows the severity of sore throat in both the groups. From the graph it is evident that group D patients had lesser grades of POST. None of the patients in group D had more than grade 1 POST. Where as in group M 8 patients at $0 \mathrm{hr}, 15$ patients at $4^{\text {th }}$ hr, 14 patients at $8^{\text {th }} \mathrm{hr}$ and 2 patients at $12 \mathrm{hr}$ had grade
2 POST. No patients had severe POST that required further treatment.

27patients in group $M$ complained of vicks like taste/ smell in the throat after nebulisation. No such complaints were given by patients in group $\mathrm{D}$.

Table 2: Comparison of incidence of post-operative sore throat, cough and hoarseness of voice

\begin{tabular}{|c|c|c|c|c|}
\hline Time & Occurrence & Group M, n (\%) & Group D, n (\%) & P-value \\
\hline \multicolumn{5}{|c|}{ Pain at Rest } \\
\hline \multirow[t]{2}{*}{ O HRS } & No & $24(60)$ & $33(82)$ & \multirow[t]{2}{*}{$0.0262 *$} \\
\hline & Yes & $16(40)$ & $7(18)$ & \\
\hline \multirow[t]{2}{*}{$4 \mathrm{HRS}$} & No & $17(43)$ & $33(82)$ & \multirow[t]{2}{*}{$0.00022 *$} \\
\hline & Yes & $23(57)$ & $7(18)$ & \\
\hline \multirow[t]{2}{*}{$8 \mathrm{HRS}$} & No & $19(47)$ & $34(85)$ & \multirow[t]{2}{*}{$0.00039 *$} \\
\hline & Yes & $21(53)$ & $6(15)$ & \\
\hline \multirow[t]{2}{*}{$12 \mathrm{HRS}$} & No & $28(70)$ & $39(97)$ & \multirow[t]{2}{*}{$0.000657 *$} \\
\hline & Yes & $12(30)$ & $1(3)$ & \\
\hline \multirow[t]{2}{*}{$24 \mathrm{HRS}$} & No & $39(97)$ & $39(97)$ & \multirow[t]{2}{*}{1.000} \\
\hline & Yes & $1(3)$ & $1(3)$ & \\
\hline \multicolumn{5}{|c|}{ Pain on Swallowing } \\
\hline \multirow[t]{2}{*}{ O HRS } & No & $30(75)$ & $33(82)$ & \multirow[t]{2}{*}{0.4122} \\
\hline & Yes & $10(25)$ & $7(18)$ & \\
\hline \multirow{2}{*}{$4 \mathrm{HRS}$} & No & $17(43)$ & $33(82)$ & \multirow[t]{2}{*}{$0.00022 *$} \\
\hline & Yes & $23(57)$ & $7(18)$ & \\
\hline \multirow[t]{2}{*}{$8 \mathrm{HRS}$} & No & $19(47)$ & $34(85)$ & \multirow[t]{2}{*}{$0.0039 *$} \\
\hline & Yes & $21(53)$ & $6(15)$ & \\
\hline \multirow[t]{2}{*}{$12 \mathrm{HRS}$} & No & $29(72)$ & $39(97)$ & \multirow[t]{2}{*}{$0.000044^{*}$} \\
\hline & Yes & $11(28)$ & $1(3)$ & \\
\hline \multirow[t]{2}{*}{$24 \mathrm{HRS}$} & No & $38(95)$ & $39(97)$ & \multirow[t]{2}{*}{1.0000} \\
\hline & Yes & $2(5)$ & $1(3)$ & \\
\hline \multicolumn{5}{|c|}{ Hoarseness } \\
\hline \multirow[t]{2}{*}{ O HRS } & No & $27(68)$ & $40(100)$ & \multirow[t]{2}{*}{$0.00414^{*}$} \\
\hline & Yes & $13(32)$ & $0(0)$ & \\
\hline \multirow[t]{2}{*}{4 HRS } & No & $24(60)$ & $35(88)$ & \multirow[t]{2}{*}{$0.00518 *$} \\
\hline & Yes & $16(40)$ & $5(12)$ & \\
\hline \multirow[t]{2}{*}{$8 \mathrm{HRS}$} & No & $24(60)$ & $40(100)$ & \multirow[t]{2}{*}{$0.0041 *$} \\
\hline & Yes & $16(40)$ & $0(0)$ & \\
\hline \multirow[t]{2}{*}{12 HRS } & No & $37(92)$ & $40(100)$ & \multirow[t]{2}{*}{0.3049} \\
\hline & Yes & $3(8)$ & $0(0)$ & \\
\hline
\end{tabular}




\begin{tabular}{|l|c|c|c|c|}
\hline \multirow{2}{*}{24 HRS } & No & $40(100)$ & $40(100)$ & \multirow{2}{*}{1.000} \\
\cline { 2 - 4 } & Yes & $0(0)$ & $0(0)$ & \\
\hline Cough & \multicolumn{3}{|c|}{} \\
\hline \multirow{2}{*}{ O HRS } & No & $40(100)$ & $40(100)$ & \multirow{2}{*}{1.000} \\
\cline { 2 - 4 } & Yes & $0(0)$ & $0(0)$ & \\
\hline \multirow{2}{*}{4 HRS } & No & $39(97)$ & $40(100)$ & \multirow{2}{*}{1.000} \\
\cline { 2 - 4 } & Yes & $1(3)$ & $0(0)$ & \\
\hline \multirow{2}{*}{8 HRS } & No & $39(97)$ & $39(97)$ & \multirow{2}{*}{1.000} \\
\cline { 2 - 4 } & Yes & $1(3)$ & $1(3)$ & \multirow{2}{*}{1.000} \\
\hline \multirow{2}{*}{12 HRS } & No & $40(100)$ & $40(100)$ & \\
\cline { 2 - 4 } & Yes & $0(0)$ & $40(0)$ & \\
\hline \multirow{2}{*}{24 HRS } & No & $40(100)$ & $0(0)$ & \\
\cline { 2 - 4 } & Yes & $0(0)$ & & \\
\hline
\end{tabular}

\section{Discussion}

Post-operative sore throat, cough, and hoarseness of voice are common, uncomfortable, distressing sequelae after tracheal intubation. Throat irritation in the presence of a large abdominal or thoracic incision can be very annoying especially in the presence of inadequate analgesia since any attempt to cough to clear the throat causes severe pain. The contributing factors for POST include young age, females, gynaecological surgery, use of succinylcholine, larger tracheal tubes, high cuff pressure. ${ }^{3-5}$

POST can be multifactorial in origin, including mechanical injury during laryngoscopy and intubation causing aseptic inflammation, continuous pressure by the inflated tracheal tube cuff on tracheal mucosa causing damage and dehydration of the mucosa. $6,13,19,20,23$

Although many drugs are used through different routes to relieve the POST, these could result in unwanted side effects. Ketamine gargle might cause adverse hemodynamic effects and taste may not be acceptable. Higher doses of drugs are required when used through intravenous route causing unwanted side effects. Gargling requires patient co -operation. So we selected method of nebulistion to deliver the study drug to throat. Dose of drug used is very minimal and acts topically avoiding adverse systemic effects.

Present study shows that prophylactic dexamethasone nebulisation helps in significant reduction in incidence of sore throat at $0 \mathrm{hr}(\mathrm{P}=0.0262)$, $4^{\text {th }} \mathrm{hr}(\mathrm{P}=0.00022), 8^{\text {th }} \mathrm{hr}(\mathrm{P}=0.00039)$ and $12^{\text {th }} \mathrm{hr}(\mathrm{P}=$ 0.000657) post extubation when compared to magnesium sulphate nebulisation. Severity of sore throat also was less compared to group M. (Fig. 2) There was no incidence of moderate sore throat (grade 2) in group D patients. None of the patients in group D had hoarseness of voice. Incidence of severe sore throat (grade 3) was not found among both the groups. This may be because we used well defined inclusion and exclusion criterias and intubations were done by an experienced anaesthesiologist, duration of surgery was less than $3 \mathrm{hrs}$, cuff pressure was monitored through out the procedure and bucking on the endotracheal tube was avoided.

Usually steroids and nebulised adrenaline are used for the treatment of POST. ${ }^{18}$ Intravenous dexamethasone or hydrocortisone is used for this purpose. It has been shown that both, topical and intravenous dexamethasone had reduced the incidence of POST. ${ }^{13,14,18}$ But glucose intolerance, fluid retention are concerns with the use of intravenous steroids. So we used nebulised dexamethasone at a dose of $8 \mathrm{mg}$. Widespread recognition of under treatment of sore throat by clinicians has led to the development of preemptive strategies for its alleviation. So we used nebulisation just before the induction of anaesthesia.

Our study showed significantly lower incidence POST in dexamethasone group at all points of assessment. This was similar to the results of Salama et al. ${ }^{21}$

Tabari et $\mathrm{al}^{22}$ studied the effectiveness of betamethasone gel applied to the tracheal tube and intravenous Dexamethasone on POST on 225 ASAI and ASAII patients undergoing elective abdominal surgery with tracheal intubation who were randomly allocated into three groups: the betamethasone gel group, the intravenous dexamethasone group and control group. They concluded that widespread application of betamethasone gel over tracheal tubes effectively reduced POST, compared to intravenous dexamethasone.

These findings are consistant with the topical application of steroid on the upper airway before endotracheal intubation.

Magnesium sulphate gargle ${ }^{10}$ and lozenges ${ }^{11}$ have been used for treating POST. We selected magnesium sulphate nebulistion to avoid large doses and for ease of administering the drug. Not much literature is available about the use of nebulized magnesium sulfate for attenuation of POST. Blitz et al. ${ }^{24}$ used nebulised magnesium sulphate for the treatment of acute asthma without any systemic and local adverse outcomes. To the best of our knowledge, there is currently no study that compares the efficacy of nebulised dexamethasone 
with that of nebulised magnesium sulphate on the incidence and severity of POST.

In Borzan et al ${ }^{11}$ study, there was a significantly decreased incidence of POST when subjects sucked on a lozenge containing magnesium preoperatively at $2^{\text {nd }}$ $\mathrm{hr}$ and $4^{\text {th }} \mathrm{hr}$ but not immediately or $24 \mathrm{hrs}$ postoperatively.

Incidence of POST is more common at $4^{\text {th }}$ to $6^{\text {th }} \mathrm{hr}$ is due to the gradually developing local Inflammation. But in Our study, more than $50 \%$ of patients (Table 2) in magnesium sulphate group had significant POST at $4^{\text {th }} \mathrm{hr}$ and $6^{\text {th }} \mathrm{hr}$. This shows that magnesium sulphate is not very effective in controlling POST. Even though incidence of POST was not significantly reduced with the use of nebulised magnesium sulphate, there was significantly reduced incidence of cough. In our study, group $\mathbf{M}$ patients who complained of hoarseness had prolonged duration of surgery (>120 min). This may be the cause, because of prolonged cuff pressure causing irritation of mucosa and odema of vocal Cords. ${ }^{25}$ So in our study magnesium sulphate nebulisation did not reduce the incidence of POST, but had a role in attenuating the severity of sore throat since none of the patients had grade 3 POST in group $\mathrm{M}$ also.

In the present study, the overall incidence of POST was $27.5 \%$ in group D and $57.5 \%$ in group M which is the same as evaluated by Macario et al. ${ }^{2}$ Even though few patients in magnesium sulphate group had relief from sore throat, it was not statistically significant.

\section{Limitations of the Study}

Firstly we did not use humidity moisture exchanger in the gas delivery circuit and dry gases are implicated in the development of postoperative sore throat 19 . Secondly we don't know how efficient is dexamethasone nebulistion in relieving sore throat in case of multiple attempts at laryngoscopy, prolonged intubation due to long procedures, use of bougies. Repetation of the nebulistion can be considered postoperatively in these patients. Thirdly the scale used to assess POST was a subjective scale and may be associated with bias.

\section{Conclusion}

Preoperative dexamethasone nebulisation just before induction of anaesthesia is an effective method of reducing the incidence and severity of POST following endotracheal intubation. Magnesium sulphate has a role in reducing the severity of sore throat. So we conclude that preoperative dexamethasone nebulisation reduces the incidence and severity of sore throat more effectively than magnesium sulphate nebulisation.

\section{References}

1. Alex Macario, Matthew Weinger, P. Truong and M. Lee. Which Clinical Anesthesia Out comes Are Both Common and Important to Avoid? The Perspective of a Panel of
Expert Anesthesiologists. Anesth Analg. 1999;88:108591.

2. Macario A, Weinger M, Carney S, Kim A. Which clinical anesthesia outcomes are important to avoid? The perspective of patients. Anesth Analg. 1999;89:652 -8.

3. Mc Hardy FE, Chung F. Postoperative sore throat cause, prevention and treatment. Anaesthesia. 1999;54(5):44453.

4. Kalil D M, Silvestro L S, Austin P N. Novel Preoperative Pharmacologic Methods of Preventing Postoperative Sore Throat due to Tracheal Intubation. AAAA Journal. 2014;82(3)188-197.

5. Higgins PP, Chung F, Mezei G. Postoperative sore throat after ambulatory surgery. Br J Anaesth. 2002;88:582584.

6. A Rudra, Suchanda Ray, S Chatterjee, A Ahmed, and S Ghosh. Gargling with ketamine attenuates the postoperative sore throat. Indian J Anaesth. 2009;53(1):40-43.

7. Ahuja V, Mitra S and Sarna R. Nebulized ketamine decreases incidence and severity of post operative sore throat. Indian J Anaesth. 2015;59(1):37-42.

8. Banihashem N, Alijanpour E, Hasannasab B, Zarei A. Prophylactic effects of lignocaine or beclomethasone spray on postoperative sore throat and cough after orotracheal intubation. Iran J Otorhinolaryngol. 2015;2 (80):179-84.

9. Bagchi D, Mandal MC, Das S, Sahoo T, Basu SR, Sarkar $S$, et al. Efficacy of intravenous dexamethasone to reduce incidence of postoperative sore throat: A prospective randomized controlled trial. J Anaesthesiol Clin Pharmacol. 2012;28:477-80.

10. Teymourian H, Mohajerani SA, Farahbod A. Magnesium and ketamine gargle and postoperative sore throat. Anesth Pain Med. 2015;5:e22367.

11. Borzan H, Kececioglu A, Okesli S, Otelcioglu S. Oral magnesium lozenge reduces postoperative sore throat: A Randomized Prospective, Placebo Controlled Study. Survey of Anesthesiolog. 2013:57(1):36.

12. Tumulu R Rao, C Subrahmanyam, Ankur Parmar, Shailesh Patil. Effect of Nebulised Lignocaine for the treatment of Post -Operative sore throat. Indian Journal of Scientific Study. September 2015;3(6).

13. Zhao X, Cao X, Li Q. Dexamethasone for the prevention of postoperative sore throat: a systematic review and metaanalysis. J Clin Anesth. 2015;27:45-50.

14. Sun L, Guo R, Sun L. Dexamethasone for the preventing postoperative sore throat: A meta - analysis of randomized controlled trials. Ir J Med Sci. 2014;183:593600.

15. Lin CY, Tsai PS, Hung YC, Huang CJ. L-type calcium channels are involved in mediating the anti-inflammatory effects of magnesium sulphate. Br J Anaesth. 2010;104:44-51.

16. Zhu MM, Zhou QH, Zhu MH, Rong HB, Xu YM, Qian $\mathrm{YN}$, et al. Effects of nebulized ketamine on allergeninduced airway hyperresponsiveness and inflammation in actively sensitized Brown-Norway rats. J Inflamm (Lond). 2007;4:10.

17. Mytra SN, Shah A, Kundra P, Patwa A, Ramkumar V, Divatia JV, et al. All India Difficult Airway Association 2016 guidelines for the management of unanticipated difficult tracheal intubation in adults. Indian J Anaesth. 2016;60:885-98.

18. Lee JH, Kim SB, Lee W, Ki S, Kim MH, Cho K et al. Effects of topical dexamethasone in post operative sore throat. Korean J Anesthesiol. 2017;70:58-63. 
19. Loser EA, Orr DL, Bannet GM, Stanley TH. Endotracheal tube cuff design and postoperative sore throat. Anesthesiology. 1976;45:684-7

20. Zhang W, Zao G, Li L, Zhao P. Prophylactic administration of corticosteroids for preventing postoperative complications related to tracheal intubation: A systematic review and meta- analysis of 18 randomised controlled trials. Clinical Drug Investigation. 2015,

21. Salama AK, El-badawy AM. Does nebulized dexamethasone decrease the incidence of postextubation sore throat? A randomized controlled study. Ain-Shams journal of Anaesthesiology. 2016;9(1):104-107

22. Tabari M, Soltani G, Zirak N. Comparision of effectiveness of betamethasone gel applied to the tracheal tube and iv dexamethasone on postoperative sore throat: a randomized controlled tria. Iran J Otorhinolaryngol. 2013;25: 215-220.

23. Park SH, Han SH, Do SH, Kim JW, Rhee KY, Kim JH. Prophylactic dexamethasone decreases the incidence of sore throat and hoarsness after tracheal intubation with a double-lumen endobronchial tube. Anesth Analg. 2008;107(6):1814-8

24. Blitz M, Blitz S, Hughes R, Diner B, Beasley R, Knoop J, et al. Aerosolised magnesium sulphate for acute asthma: a systematic review. Chest. 2005;128:337-44.

25. Liu J, Zhang X, Gong W. correlations between controlled endotracheal tube cuff pressure and postprocedural complications: a multicenter study. Anesth Analg. 2010;111:1133-1137.

26. DM Doukumo, AF Faponle, SOA Olateju. Effects of lidocaine and K-Y jellies on sore throat, cough, and hoarseness following endotracheal anaesthesia.

27. Sumathi PA, Shenoy T, Ambareesha M, Krishna HM. Controlled comparison between betamethasone gel and lidocaine jelly applied over tracheal tube to reduce postoperative sore throat, cough, and hoarseness of voice. Br J Anaesth. 2008;100:215-8.

28. Ozaki M, Minami K, Sata T, Shigematsu A: transdermal ketoprofen mitigates the severity of postoperative sore throat: Can J Anaesth. 2001;48:1080-3.

How to cite this article: Ashwini H, Kumari SK, Lavanya R. Comparative study of dexamethasone nebulisation with magnesium sulphate nebulisation in preventing post operative sore throat following endotracheal intubation. Indian $\mathbf{J}$ Clin Anaesth. 2018;5(3):341-347. 